\title{
Squaring the circle by attempting to teach a lab class in the cloud - reflections after a term in lockdown
}

Thomas A. Logothetis, * Colin M. Flowers

Department of Chemistry, University of Southampton, Highfield Campus, University Road,

5 Southampton SO17 1BJ, United Kingdom

\author{
ABSTRACT \\ Whether it is prolonged strike action, a protest movement or a global viral outbreak, the
} disruptions triggered in higher education are profound. In a STEM subject, laboratory classes are vital to teaching and learning. Chemistry educators had to transport laboratory skills-based teaching and assessment courses to the virtual world at short notice, whilst adhering to evolving university policies. Analysis of the situation from the perspective of the lecturer and the student revealed for a laboratory class setting that student engagement did not significantly change throughout the semester and was relatively high compared to other teaching activities. During the lockdown students embraced traditional pathways for seeking support and reluctantly adopted new opportunities presented to staff and students alike at the start of the closure period. More active and interactive formats failed to take proper hold mainly due to a combination of technology (restrictions in available bandwidth and hardware) and anxiety issues. Undergraduate students, however, do wish to engage with their studies and if the difficulties identified herein can be addressed adequately, the scene can be set for a successful and supportive teaching and learning environment in a socially distanced lab class combined with improved online support. It would include a structured and prescribed participation in partly online, partly live teaching sessions that are summatively assessed. This must be supported by a formal induction to the available IT infrastructure as well as assurances that learning in open fora enriches the learning experience and should not cause nervousness. Sticking to the published timetable for synchronous delivery and additional asynchronous support opportunities will assisted students in planning and undertaking a balanced workload, and the social aspects and value of faceto-face time in a blended teaching approach must be emphasised. 


\section{GRAPHICAL ABSTRACT}

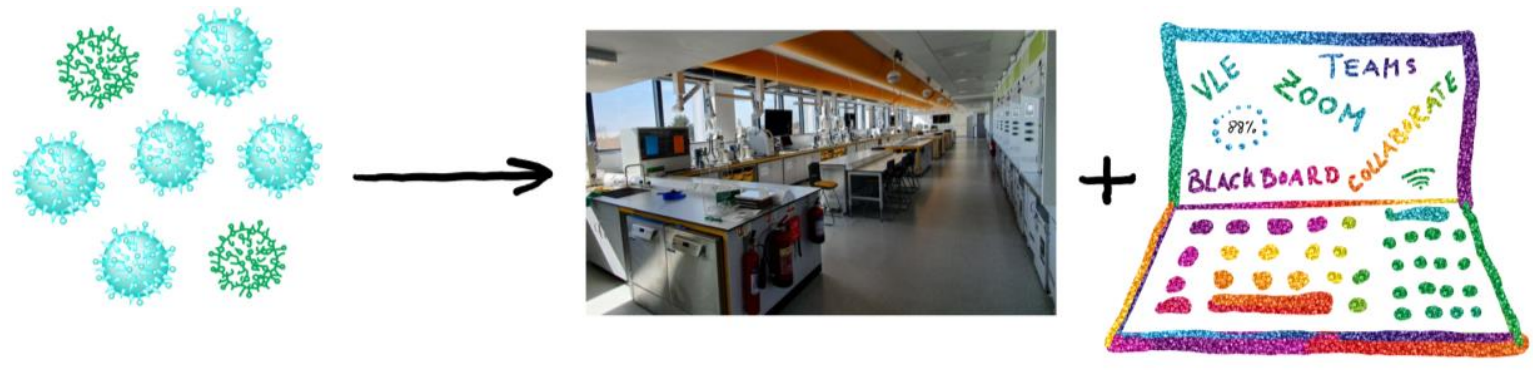

\section{KEYWORDS}

General Public, First-Year Undergraduate / General, Second-Year Undergraduate, Interdisciplinary / Multidisciplinary, Distance Learning / Self Instruction, Internet / Web-Based Learning, MultimediaBased Learning, Learning Theories.

\section{INTRODUCTION}

It was less than two years ago when Marietjie Potgieter ${ }^{1}$ spoke about "Lessons Learnt from Teaching and Learning during Disruptions" in the final plenary of the International Conference on Chemistry Education in Sydney, Australia, as Thomas Holme evoked in his editorial. ${ }^{2}$ In her fascinating talk, she described and analysed the severe and long-term disruption to teaching chemistry at the University of Pretoria, South Africa. The corresponding author's take-away messages about such a seemingly unique situation were rudimentary: students are not self-motivated in isolation, especially not in the longer term, they prefer scheduled activities and value face-to-face interaction with lecturers to overcome poor selfregulation and to enhance motivation, particularly in weaker students. The students were keen on interpersonal contact with peers and teachers as they missed the social aspects of being on campus. Technology problems required creative solutions for a wide variety of socioeconomic backgrounds and diverse cultural cohorts. Having worked there as a postdoctoral research fellow some time ago with a colleague of Marietjie Potgieter, I could picture the circumstances very well, but little did I imagine that the circle had to be squared again so soon in what is now an almost ubiquitous perturbation in the time of COVID-19. In this communication, the authors reflect on their transition from actual laboratory managers to teaching practical classes in a virtual learning environment (VLE) and how the students reacted to this new ecosystem. 


\section{BACKGROUND}

State of affairs

The raisons d'être for teaching practical laboratory classes in chemistry are still debated ${ }^{3}$ and according to Seery, ${ }^{4}$ the pedagogical basis for improving laboratory education is in a process of reevaluating what makes them stand out. Overton et al. ${ }^{5}$ compared student and staff perceptions about the aims of a practical course and found that academics often hold narrower views than students but overall agree that the goals include inter alia the development of technical skills through hands-on, active learning as well as transferable skills like managing time effectively and communicating concisely and scientifically. The psychomotor domain from Bloom's taxonomy was also picked up by Bretz et al. ${ }^{6}$ who found that students, in particular, see the tactile experience as the rationale for laboratory classes.

Although some of these skills would be learnt in a laboratory setting, there have been efforts to enhance the experience through pre-laboratory resources and videos in a virtual environment in an attempt to incorporate a flipped approach to teaching practical chemistry..$^{7,8}$ Davenport et al. ${ }^{9}$ realised that students gained through a virtual support to the chemistry lab and Blackburn et al. ${ }^{10}$ described the positive effect laboratory simulations had when students had an opportunity to utilize them before entering the laboratory; finding them better prepared and attaining more skills, whereas students emphasised their improved time-management. Videos specifically constructed on Johnstone's triangle model supported students preparation for and learning during lab classes particularly well through embedded interactive questions. ${ }^{11}$ However, it is acknowledged that despite their benefits, computergenerated simulations and online resources alone cannot replicate the practice and authentic experience of a real laboratory class but rather complement them. ${ }^{12}$

The shift in attitude towards laboratory instruction is also reflected in recent articles about laboratory assessment. This requires a close look at learning outcomes and skills matrices relevant to practical instruction ${ }^{13,14}$ and formulating desired key competencies ${ }^{15}$. This has led to the development of skills assessment in a laboratory under exam-like conditions ${ }^{16,17}$ or using rubrics in a system ${ }^{18}$ that is transferable to many different scenarios and versatile with different lab instructors. 
It therefore becomes clear that studying chemistry without laboratory classes, as had to happen during the disruption, would replace certain aspects, e.g. haptic experience and feedback on practical lab skills, with new and additional online resources that can accentuate other aspects instead.

The starting point - context and resources

Herein, the laboratory managers shed light on their experience with teaching lab classes exclusively

online. The focus is on undergraduate students taking practical classes associated with core chemistry modules in the first year (CHEM1032, CHEM1034, CHEM1036) and the second year (CHEM2005, CHEM2012, CHEM2016); complementing inorganic, organic and physical chemistry lecture courses.

It was also decided to capture formative student feedback with a view to improve the online lab teaching provision in the next academic year as it was recognised that the laboratory closure might continue or only be removed partially. Students $(\mathrm{N}=106,25$ responses, 24\%, details in supporting information) were therefore invited to describe their experience and they conveyed it through a questionnaire as well as during the teaching activities.

At the University of Southampton, the VLE currently used is Blackboard Collaborate, linked with Panopto video and lecture capturing. The university software suite for communication is Microsoft Teams. Additionally, the Windows Ink Workspace / Whiteboard feature was made available. Moreover, touchscreen tablets with pens normally used by students in the teaching laboratories were distributed to staff in the department. Also, connectivity via virtual private network (VPN or Southampton Virtual Environment, SVE) was significantly increased to accelerate access to resources on the intranet, e.g. the library, software and instrument data.

Students and lecturers were already enrolled to the VLE which hosts a dedicated laboratory course for each of the two year groups. Furthermore, students were provided with instructions on how to sign up to a laboratory Teams account - one for the laboratory as a whole, divided into channels for each practical - for additional features and to establish ways for online face-to-face contact options.

The interruption to campus teaching happened in Southampton, United Kingdom, at the end of spring term. This provided, over the four week Easter break, vital time for the IT and education departments to fast-track installation of new software features, disseminate expertise in online teaching, and to enhance training resources, first aimed at staff and later in a designated induction week also at 
students. The Easter break also afforded time in which new resources for students could be tested, developed and deployed before the start of the summer term. The disruption to face-to-face teaching came with little warning but crucially, the time to prepare for the next term was longer than the circumstances reported by Potgieter. ${ }^{1}$

\section{FINDINGS AND DISCUSSION}

\section{Experiences during the closure - the academics side}

Additional resources to support independent learning were newly created to supplement the existing

VLE comprising videos, quizzes, techniques videos, automated and rubric grading. Particular emphasis was given to inquiry-based episodes as it was envisaged that lab-based group discussions could not be replicated online. Therefore, videos were produced to stimulate independent learning. Additionally, labbased skills assessment was replaced by a focus on interpretation of sample data. New instructions were posted to detail these changes and how to construct the reports.

In a typical example, students read the script and watch a video ${ }^{19}$. Instead of performing the practical, they were given experimental data and a sample cyclic voltammogram for analysis. This allowed them to determine the glucose content of a lemonade. The video establishes a link between the practical, theoretical background and the real world and has been shot in the teaching laboratory. During lockdown it served as a substitute for actually entering the lab to perform the experiments and discussing with a demonstrator. During closure of the university campus, the recording in the laboratory could be replaced by a virtual setting or stock pictures.

Feedback from students indicates that for the virtual lab classes the requirements were made clear and that the guidelines were useful. Outcomes from student consultation revealed a preference for short videos and lecturers using this technique had a better student engagement. Lecture-capturing software was used for the creation of videos and those that allowed simplified editing were found most useful. However, some colleagues found more creative solutions, like filming themselves drawing on a whiteboard, paper or a screen, helpful. Students commented positively on the combination of lecturer visibility and chemistry content; and they also found that lab topics complemented lectures as these aided the understanding of associated theory. 
Overall, the assessment structure was changed to a no-detriment policy that effectively allowed students to improve their marks (and understanding) through participation but shifted to a more formative character. For the laboratory, report submission with extended deadlines would satisfy the otherwise mandatory lab attendance at classes, which hinted at a summative aspect.

The effects on student participation was mixed, and for lectures and tutorials it was chiefly reported as lower than usual. The voluntary character has not worked well as in a formative setting the motivation was lost. This is evidenced by qualitative feedback from most lecturers who reported that attendance at virtual sessions and participation in online classrooms was minimal and when discussion turned with the partaking students to the reasons, the lack of marks was given repeatedly. While the summative situation with virtual lab classes differed, the authors also received student comments that pointed to the lack of value of formative settings during the lockdown. Clearly, grades matter to students and drive their engagement with the course material and teaching support. In a continued closure situation this, has to be taken into account for example through a participation token similar to what Seery ${ }^{20,21}$ suggests for lab competencies. It also serves as a reminder of the benefits of mandatory lecture and tutorial attendance.

For lab classes the outcome was much better, as shown in Table 1 which examines submissions before and after lockdown. The high submission rate that does not change significantly pre or post lockdown is attributed to linking compulsory lab attendance, i.e. report submission during lockdown, to progression. Issues about academic integrity did not arise during the entire semester.

\begin{tabular}{|c|c|c|c|}
\hline \multicolumn{2}{|c|}{ Post Lockdown } & \multicolumn{2}{|c|}{ Pre Lockdown } \\
\hline $\begin{array}{c}\text { Number of } \\
\text { expected } \\
\text { submissions }\end{array}$ & $\begin{array}{l}\text { Received } \\
\text { reports }\end{array}$ & $\begin{array}{l}\text { Number of } \\
\text { attended lab } \\
\text { classes }\end{array}$ & $\begin{array}{l}\text { Submitted } \\
\text { reports }\end{array}$ \\
\hline 363 & $83 \%$ & 589 & $87 \%$ \\
\hline
\end{tabular}

To increase interactivity via peer learning and facetime with lecturers, Microsoft Teams were created

with individual channels for each practical. It was envisaged that the shared online Teams whiteboard facility together with video contact would be best suited to solicit engagement and support student learning. 
To increase student engagement during lockdown, each non submission was followed up by email and in almost half the cases this resulted in further active participation $(\mathrm{N}=43,44 \%)$. This reminder would have been given verbally and less regularly during lab classes.

Realising that deviating from the student schedule could result in teaching activities becoming spread to suit the lecturers' availability and an imbalanced demand on students' time might develop as undesirable outcome, the university decided to stick to the published timetable for all teaching activities to avoid cognitive overload and clashes. However, the lab managers increased their availability to accommodate additional question and answer sessions for students living in different time zones and allowed access to their calendar to facilitate meeting requests outside scheduled lab class slots. This latter aspect provided a certain degree of freedom that was also taken up by local students.

\begin{tabular}{|c|c|c|}
\hline \multicolumn{3}{|c|}{ Table 2: Student support demanda } \\
\hline \multirow[t]{2}{*}{ Contact type } & \multicolumn{2}{|c|}{$\begin{array}{c}\text { Average number of contacts } \\
\text { per week }\end{array}$} \\
\hline & $\begin{array}{c}\text { before } \\
\text { lockdown }\end{array}$ & $\begin{array}{c}\text { during } \\
\text { lockdown }\end{array}$ \\
\hline Email & 15.1 & 16.5 \\
\hline Online $^{b}$ & $-c$ & 4.1 \\
\hline \multicolumn{3}{|c|}{$\begin{array}{l}\text { a During semester 2, across years } 1 \text { and } 2 \\
\text { b Audio or video meeting, online chat } \\
\text { c Facility did not exist at the time }\end{array}$} \\
\hline
\end{tabular}

Overall, student support as measured by online interaction did increase slightly (see Table 2) but mainly via the traditional route (asynchronous, individual basis) and not as anticipated via the newly introduced Teams facilities (open chats or interactive video meetings). This might be attributed partly to a preference for traditional methods students are familiar with from the time before lockdown, i.e. directly contacting the laboratory teacher on an individual basis as and when a question arises. However, the feedback from students (vide infra) also points at anxiety about opining publicly, i.e. asking questions or partaking in a live-online session, e.g. a chat that is visible to the entire cohort or group video calls.

Post activity feedback - the student voice

While there appeared no striking problems with the delivery and participation in the online lab course, it was considered prudent to learn about student experiences and their concerns with a view to take their suggestions for improvement forward when designing the next year's classes. Several formal opportunities for staff-student exchange of ideas, criticism, constructive feedback and evaluation exist 
during a typical academic year. However, in the context of the externally imposed situation and the speed of implementation of the cloud-based lab teaching, the authors solicited feedback from the students and around a quarter of the cohort obliged through a questionnaire (see SI). In addition, comments from students during any of the teaching activities were noted.

It was revealed that around half of the students did not contact academic teaching staff; this was because they felt they required no assistance and it was not the case that non-contact was due to a failure of understanding how to do so or to IT issues. Only $20 \%$ stated the no-detriment policy as their reason for not seeking contact. Satisfyingly, almost all respondents (96\%) engaged with the virtual laboratory class in the cloud and submitted reports.

The preferred route of contact with academic teaching staff (see Table 3) was found to be email contact, an asynchronous method that applies also to recorded video. A possible delay in receiving a response is offset by the opportunity to revisit the resource repeatedly. The live or synchronous pathways included chats, Teams meetings, and sharing of a screen, a selected document or an electronic whiteboard. Teams was chosen by the authors (over Blackboard Collaborate) for its versatility and intuitive use and because it simplifies use of these features. Pleasingly, $40 \%$ of the students shared that preference while another $45 \%$ reported that it worked as well as Blackboard Collaborate for them.

\begin{tabular}{|c|c|}
\hline Type & Percentage \\
\hline Email & $91 \%$ \\
\hline Chat & $18 \%$ \\
\hline Screenshares ${ }^{a}$ & $18 \%$ \\
\hline Teams meetings ${ }^{b}$ & $9 \%$ \\
\hline Electronic whiteboardc & $9 \%$ \\
\hline \multicolumn{2}{|c|}{$\begin{array}{l}\text { a Passive use in viewing mode } \\
\text { b Audio / video } \\
\text { c Bidirectional interaction }\end{array}$} \\
\hline
\end{tabular}

Using the whiteboard in interactive mode allowed the student to answer questions by drawing rather than just describing the result (as could be done in a standalone video meeting). In chemistry this is an important feature when discussing mechanisms, calculations, spectra, graphs or structures. It is also a familiar setting comparable to a live lab class or tutorial. However, for it to be truly interactive and useful, a touch screen with pen is indispensable, as drawing with the mouse or finger is totally 
ineffective. One explanation for students using this feature sparingly lies in the low availability of touchscreens $(45 \%)$ and pens $(27 \%)$ while all had access to computing. Other reasons for not using online meetings include internet connectivity issues that are summarised in Table 4.

\begin{tabular}{|c|c|}
\hline Type & Percentage \\
\hline Time zone-related & $10 \%$ \\
\hline Slow to normal internet speed & $36 \%-64 \%{ }^{a}$ \\
\hline Shared bandwidth & $91 \%$ \\
\hline Data limit / metered service & $9 \%$ \\
\hline
\end{tabular}

Moreover, the survey illuminates another motive for the penchant of email over a more open chat or live video session: $55 \%$ of the responses indicate that anxiety about sharing questions or opinions in a chat group setting is to blame, while a comparable proportion (50-64\%) shy away from video meetings for the same reason.

\section{CONCLUSION}

In summary, internet connection and technology issues played a role in student engagement as well as staff delivery. Some of these could be resolved by the university (e.g. provision of hardware) while others depend on third parties (e.g. time and bandwidth available to each student). Anxiety was a key factor preventing students from a deeper, high level interaction with the teacher. This has to be addressed through support groups and by a clear terms of reference framework that emphasises the rich gains over possible fears of making mistakes.

Our experiences over the last term indicate that students do engage, and much more so when the teaching provision is structured and participation is prescribed. Bandwidth and hardware issues are hopefully less of a concern in future, as society adapts to a new normal. But universities have to consider these aspects to avoid disadvantaging users off campus in any scenario that involves significant home office work or study. Participation can also be increased by automatic massenrolment at cohort level at the start of the academic year. Alternatively, a more detailed and formalised induction session with the undergraduate students could feature an on-the-spot joining event and test run to become instantly familiar with the benefits of e.g. an open chat and discussion forum. 
Anxiety using more open platforms has been identified as hindering a fuller experience and facetime with tutors and peers is valuable-and should be replicated in any virtual scenario. In a situation with open laboratories, social distancing will likely remain in place and the online delivery of content will play an important role, possibly even in class and definitely for those - academics and students alike - required to shield until a cure or safe infection prevention has been established.

Squaring the circle is, of course, not possible without tools. In our times and modern environment with plentiful and powerful IT resources an imperfect attempt has been made, though, in the virtual world. It is hoped that this communication assists the community in designing better courses in the next term and shaping a more blended laboratory course in a new future beyond the COVID-19 crisis.

\section{ASSOCIATED CONTENT}

The Supporting Information is available on the ACS Publications website at DOI:

\subsection{1/acs.jchemed.XXXXXXX. [ACS will fill this in.]}

Student feedback (PDF)

\section{AUTHOR INFORMATION}

*E-mail: thomas.logothetis@soton.ac.uk

\section{ACKNOWLEDGMENTS}

The authors gratefully acknowledge the feedback from colleagues and students during the creation of the virtual resources and the remote, online delivery of the course during lock down. Special thanks are due to the members of the education and IT departments, respectively, for their on-going, patient and tireless support after implementing new features and for providing training and resources for students and colleagues in their efficient use. The authors would like to thank Thomas A. Holme for constructive critique before the preparation of this contribution.

\section{REFERENCES}

1. Potgieter, M.; Pilcher, L. A.; Tekane, R. R.; Louw, I.; Fletcher, L., Lessons Learnt from Teaching and Learning During Disruptions. In Research and Practice in Chemistry Education: Advances from the 
25th IUPAC International Conference on Chemistry Education 2018, Schultz, M.; Schmid, S.; Lawrie, G. A., Eds. Springer Singapore: Singapore, 2019; pp 89-107. 10.1007/978-981-13-6998-8_6

2. Holme, T. A., Journal of Chemical Education Call for Papers: Special Issue on Insights Gained While Teaching Chemistry in the Time of COVID-19. Journal of Chemical Education 2020, 97 (5), 1226-1227. 10.1021/acs.jchemed.0c00378

3. Reid, N.; Shah, I., The role of laboratory work in university chemistry. Chemistry Education Research and Practice 2007, 8 (2), 172-185. 10.1039/B5RP90026C

4. Seery, M. K., Establishing the Laboratory as the Place to Learn How to Do Chemistry. Journal of Chemical Education 2020, 97 (6), 1511-1514. 10.1021/acs.jchemed.9b00764

5. George-Williams, S. R.; Ziebell, A. L.; Kitson, R. R. A.; Coppo, P.; Thompson, C. D.; Overton, T. L., 'What do you think the aims of doing a practical chemistry course are?' A comparison of the views of students and teaching staff across three universities. Chemistry Education Research and Practice 2018, 19 (2), 463-473. 10.1039/C7RP00177K

6. Galloway, K. R.; Malakpa, Z.; Bretz, S. L., Investigating Affective Experiences in the Undergraduate Chemistry Laboratory: Students' Perceptions of Control and Responsibility. Journal of Chemical Education 2016, 93 (2), 227-238. 10.1021/acs.jchemed.5b00737

7. Winkelmann, K.; Keeney-Kennicutt, W.; Fowler, D.; Macik, M., Development, Implementation, and Assessment of General Chemistry Lab Experiments Performed in the Virtual World of Second Life. Journal of Chemical Education 2017, 94 (7), 849-858. 10.1021/acs.jchemed.6b00733

8. Smith, D. K., iTube, YouTube, WeTube: Social Media Videos in Chemistry Education and Outreach. Journal of Chemical Education 2014, 91 (10), 1594-1599. 10.1021/ed400715s

9. Davenport, J. L.; Rafferty, A. N.; Yaron, D. J., Whether and How Authentic Contexts Using a

275 Virtual Chemistry Lab Support Learning. Journal of Chemical Education 2018, 95 (8), 1250-1259. 10.1021 /acs.jchemed.8b00048

10. Blackburn, R. A. R.; Villa-Marcos, B.; Williams, D. P., Preparing Students for Practical Sessions Using Laboratory Simulation Software. Journal of Chemical Education 2019, 96 (1), 153-158. 10.1021/acs.jchemed.8b00549

28011 . Petillion, R. J.; McNeil, W. S., Johnstone's Triangle as a Pedagogical Framework for FlippedClass Instructional Videos in Introductory Chemistry. Journal of Chemical Education 2020, 97 (6), 1536-1542. 10.1021/acs.jchemed.9b01105

12. Penn, M.; Ramnarain, U., South African university students' attitudes towards chemistry learning in a virtually simulated learning environment. Chemistry Education Research and Practice 2019, 20 (4), 699-709. 10.1039/C9RP00014C

13. Veale, C. G. L.; Jeena, V.; Sithebe, S., Prioritizing the Development of Experimental Skills and Scientific Reasoning: A Model for Authentic Evaluation of Laboratory Performance in Large Organic Chemistry Classes. Journal of Chemical Education 2020, 97 (3), 675-680.

10.1021/acs.jchemed.9b00703

290 14. Adams, C. J., A Constructively Aligned First-Year Laboratory Course. Journal of Chemical Education 2020. 10.1021/acs.jchemed.0c00166

15. Pullen, R.; Thickett, S. C.; Bissember, A. C., Investigating the viability of a competency-based, qualitative laboratory assessment model in first-year undergraduate chemistry. Chemistry Education Research and Practice 2018, 19 (2), 629-637. 10.1039/c7rp00249a

295 16. Hancock, L. M.; Hollamby, M. J., Assessing the Practical Skills of Undergraduates: The Evolution of a Station-Based Practical Exam. Journal of Chemical Education 2020, 97 (4), 972-979. 10.1021/acs.jchemed.9b00733

17. Mio, M. J.; Benvenuto, M. A., The Unsafe Lab Practical. Journal of Chemical Education 2020. 10.1021/acs.jchemed.0c00077

30018 Harwood, C. J.; Hewett, S.; Towns, M. H., Rubrics for Assessing Hands-On Laboratory Skills. Journal of Chemical Education 2020. 10.1021/acs.jchemed.0c00200

19. Electrochemical reactions.

https: / / www.youtube.com/watch?v=AGkJo8nLX8k\&feature=player_embedded (accessed 07/08/2020). 
305 20. Seery, M. K.; Agustian, H. Y.; Doidge, E. D.; Kucharski, M. M.; O’Connor, H. M.; Price, A., Developing laboratory skills by incorporating peer-review and digital badges. Chemistry Education Research and Practice 2017, 18 (3), 403-419. 10.1039/C7RP00003K

21. Hennah, N.; Seery, M. K., Using Digital Badges for Developing High School Chemistry Laboratory Skills. Journal of Chemical Education 2017, 94 (7), 844-848.

$310 \quad 10.1021 /$ acs.jchemed.7b00175 